\title{
The Use of Constructivist Approach in Enhancing the Students' Chemistry Achievement
}

\author{
Maria Wendy M. Solomo \\ Partido State University - School of Graduate Studies, Goa, Camarines Sur, Philippines
}

\begin{abstract}
ARTICLE INFO
Keywords:

Constructivist approach

Chemistry achievement

Cognitive skills
\end{abstract}

\section{Introduction}

Some years ago, our world is said to be a knowledge society characterized with the vast amount of information and knowledge being produced and given more importance. Now, the world is becoming not only labor-intensive, materials intensive, and knowledge-intensive; but also, a technology-dependent society which makes it more complex and a difficult place to live in. As a consequence of rapid scientific and technological advancement, the increasing complexity of life which makes scientific literacy essential for all citizens who wish to understand the world they live and work in. It is indeed imperative for the young to acquire scientific literacy which will assure their maximum participation in the attainment of progress and enjoyment of the benefits of such growth as they blossom into enlightened and responsible citizens (Sutaria, 1985). In fact, Science and Technology is regarded as a catalyst in improving the quality of life of our people. Thus, love and interest in science must be developed even at an early age.

Science education, specifically, chemistry education, has far greater roles than that of and therefore, presents greater challenges to chemistry teachers (Tsaparlis, 2016). However, the complexity of chemistry has implications for the teaching of chemistry today. Students experience difficulties in understanding Chemistry concepts in various ways such as misconceptions, preconceptions, naïve beliefs, and spontaneous reasoning. Students had misconceptions whether atoms can be viewed under a microscope, different elements consist of the same atoms, there is no space between particles in atoms and atoms only include nucleus. Confusion also exists in the following concepts: mixture and element, compound and molecule, melting and solubility, and they could not distinguish the substance that includes molecules

* Corresponding Author E-Mail Address: wendysolomo08@gmail.com 
(Avci, et al. 2014). In science, there are often many ideas that are frequently misinterpreted. This may be the result of students coping with making sense of abstract concepts. Other misconception arises from new innovations and discoveries due to old ideas or legends. Moreover, students could not relate the formation of a precipitate in a double decomposition reaction to the low solubility of the salt (Butts and Smitt, 1987). Several procedures in qualitative analysis involve redox reactions and studies have shown that students find redox difficult and confusing, De Jong, et al. 1995; Garnett and Treagust, 1992; Harrison and Treagust, 1998 (in Tan, et al. 2001). Grade 10 students (15 to 17 years old) in Singapore had difficulty understanding the reactions involved in the identification of cations and anions, for example in double decomposition, the formation, and reaction of complex salts, and thermal decomposition (Tan, et al. 2001). Likewise, students in Turkey (18 to 23 years old) had difficulty in uniting and relating the knowledge learned about acids and bases to salts (Secken, 2010).

Similarly, Filipino high school students experience the same problem and encounter the same difficulties. Most Filipino high school students get poor ratings; worse, they fail in chemistry because complex topics were not simplified and were not taught in an interesting manner (Matchete, 2001). Furthermore, Chemistry is unattractive and uninteresting to most students. Some students even shun higher chemistry due to the difficulties they encounter in high school chemistry.

Various national reports have criticized the educational system for failing to prepare students to walk a path whereby they are enabled to grow and develop as fully human persons. Based on previous studies and researches, the performance of various groups of Filipino students in science is below the accepted average in national, or international tests administered by different agencies. In an international assessment of student achievement in science and mathematics by 38 countries worldwide, the Philippines ranked 36th in science proficiency. This was the Third International Mathematics and Science Study - Repeat or TIMSS - R conducted in 1999. Moreover, based on TIMSS 2003 results, the Philippines ranked 41st in science proficiency out of 45 countries worldwide. These data show there is no improvement in our educational system.

In the Science Diagnostic Test in Chemistry administered by Fund for Assistance to Private Education (FAPE), results revealed that students of one of the private universities in Naga City had difficulty understanding some of the chemistry concept and principles. The students got low scores, based on the difference between the School Mean and Norm Group's Average Difficulty Level, in the following topics: Solutions, Gases, Matter, and Inside the Atom. The FAPE results intensified the need to develop new instructional tools to come up with recommendations on how to improve students' performance in Chemistry. The researcher developed instructional materials on Solutions using the Constructivist view of learning to enhance the students' achievement in Chemistry where students will become more reflective, inquisitive, active, and responsible decision-makers. In constructivist teaching, meaningful learning occurs as learners are actively involved in a process of meaning and knowledge construction as opposed to passively receiving information. The study also determined the specific factors in the constructivist approach that contributed significantly to students' achievement and attitude.

\section{Materials and Methods}

The study employed the quasi-experimental method of research, specifically the pretest posttest two group design, involving the researcher's two classes in General Chemistry to represent the control and experimental groups. It used both quantitative and qualitative techniques in collecting and analyzing the data. The data requirements were gathered through the use of pretest and posttest on Solutions. While, students' responses on the constructivist 
checklist, students' comments on the use of constructivist approach, and students' journal entries provided the data for qualitative analysis. The experimental class was composed of 42 students and the control class was composed of 41 students. Most of these students belong to the average group in terms of their level of intelligence as revealed by their academic grades in the previous year.

The gathering of information and data used in this study was made possible through the use of the following instruments: (a) the achievement test; (b) the Chemistry attitudinaire and evaluation form on the constructivist view of learning Chemistry ideas and concepts and (c) the Constructivist Lesson Plans. The instruments went to content validation process. Two sets of lesson plans were prepared by the researcher. One set of lesson plans covered the topic 'Solution' and was developed utilizing the constructivist approach while, the other set of lesson plans on the same topic was designed using the traditional method of teaching. The lessons using the constructivist view of learning chemistry principles and concepts adopted the social constructivist model which consists of five phases namely: orientation, elicitation, restructuring, application and review phases proposed by Driver and Oldham (1986).

The gathered data were subjected to statistical analysis. In gathering and tallying the data, simple frequency count was utilized. Item analysis was made after the pilot test to determine the difficulty index and discriminating power of each item. Then, the items in the final draft of the achievement test were formulated. The reliability of the test was determined using the computed value of the mean, standard deviation and variance. Finally, the Kuder - Richardson Formula 20 was used to find out the reliability of the test item. Results of the pretests and posttests of the control and experimental groups were tabulated and compared and the mean gain obtained by getting the difference between the mean of the posttest and the mean of the pretest on the data collected by the researcher. To the importance of the mean gain was determined through the use of effect size (ES).

The levels of achievement, categorized into high, average, and low levels, are determined arbitrarily (Table 1). The following range scale is calculated by determining the number of items per cognitive level divided by the three levels of achievement. Likewise, the overall level of achievement is determined by considering the total number of items divided by the three levels of achievement.

Table 1.

Range Scale for the Levels of Achievement

\begin{tabular}{lcccc}
\hline Level of Achievement & Comprehension & Application & Analysis & Overall \\
\hline High & $16.01-24.00$ & $14.01-21.00$ & $20.01-30.00$ & $50.01-75.00$ \\
Average & $8.01-16.00$ & $7.01-14.00$ & $10.01-20.00$ & $25.01-75.00$ \\
Low & $0.00-8.00$ & $0.00-7.00$ & $0.00-10.00$ & $0.00-25.00$ \\
\hline
\end{tabular}

Moreover, to determine the response of the student to the employment of the Constructivist Approach in Chemistry, the Likert Scaling technique of summated rating was utilized. A correlation analysis was used to determine the factors in the Constructivist Approach that significantly contributed to the students' level of achievement in the three cognitive skills: comprehension, application, and analysis. In like manner, correlation analysis was used to determine the factors in the Constructivist Approach that significantly contributed to student's attitude towards the subject.

\section{Results and Discussion}

3.1. Level of Achievement in Comprehension, Application, and Analysis Cognitive Skills

Three (3) cognitive processes in the Bloom's taxonomy namely: comprehension (also called understanding in the new Bloom's taxonomy), application/applying, and analysis/analyzing were considered to determine the level of achievement on the concepts, ideas, and principles 
about Solution. In the pre-test, all students in both groups have low level of achievement while, in the post-test, there are more students in the experimental group who got higher rating in the three cognitive skills compared with the control group as shown in Table 2.

\subsubsection{Comprehension Skill}

Based on the pretest result, along comprehension skill, the experimental group obtained a mean of 3.50 while, the control group got a mean of 3.44. On the other hand, in the post-test results, the experimental group's mean is 12.21 while, the control group's mean is 8.56 (Table 2). Before the intervention, many students did not get the correct answer because they have not yet acquired sound knowledge about the concepts and theories on the topic Solution. How can students proceed to higher thinking skills if they cannot yet comprehend or worse, they cannot even recall the important concepts on Solution? Teachers should really exert more effort to develop students' low-level thinking skills.

During the treatment, students in both groups were exposed to activities that allow them to construct meaning by inferring, comparing, interpreting, and paraphrasing. It shows that the students' comprehension skill in the experimental group is better improved after the exposure to the constructivist approach. This is reflected in their answers in the post test. For instance, after the use of the constructivist approach, the student could already distinguish solid solution from liquid solution. There is indeed a restructuring of ideas which was made possible by the activities provided by the teacher. When students are allowed to construct their knowledge and understanding, the learning is more meaningful. This result conforms to Osborne and Wittrock's idea on constructivism. They firmly believed on the importance of what learners bring with them to the learning situation. They support the idea that active construction of meaning improves students' comprehension and other cognitive skills hence, teachers should design lesson plans and learning activities that will allow students to construct their own understanding.

Table 2.

Level of Achievement in the Pre-test and Post-test PRE-TEST

\begin{tabular}{|c|c|c|c|c|c|c|c|c|c|c|c|c|}
\hline \multirow{3}{*}{ Level } & \multicolumn{4}{|c|}{ Comprehension } & \multicolumn{4}{|c|}{ Application } & \multicolumn{4}{|c|}{ Analysis } \\
\hline & \multicolumn{2}{|c|}{ Experimental } & \multicolumn{2}{|c|}{ Control } & \multicolumn{2}{|c|}{ Experimental } & \multicolumn{2}{|c|}{ Control } & \multicolumn{2}{|c|}{ Experimental } & \multicolumn{2}{|c|}{ Control } \\
\hline & $\mathrm{F}$ & $\%$ & $\mathrm{~F}$ & $\%$ & $\mathrm{~F}$ & $\%$ & $\mathrm{~F}$ & $\%$ & $\mathrm{~F}$ & $\%$ & $\mathrm{~F}$ & $\%$ \\
\hline High & 0 & 0.00 & 0 & 0.0 & 0 & 0.0 & 0 & 0.0 & 0 & 0.0 & 0 & 0.0 \\
\hline Average & 1 & 2.4 & 0 & 0.0 & 0 & 0.0 & 0 & 0.0 & 0 & 0.0 & 0 & 0.0 \\
\hline Low & 41 & 97.6 & 41 & 100 & 42 & 100 & 41 & 100 & 42 & 100 & 41 & 100 \\
\hline Overall & 42 & 100 & 41 & 100 & 42 & 100 & 41 & 100 & 42 & 100 & 41 & 100 \\
\hline Mean & \multicolumn{2}{|c|}{3.50} & \multicolumn{2}{|c|}{3.44} & \multicolumn{2}{|c|}{1.98} & \multicolumn{2}{|c|}{1.80} & \multicolumn{2}{|c|}{3.62} & \multicolumn{2}{|c|}{3.98} \\
\hline Interpretation & \multicolumn{2}{|c|}{ Low } & \multicolumn{2}{|c|}{ Low } & \multicolumn{2}{|c|}{ Low } & \multicolumn{2}{|c|}{ Low } & \multicolumn{2}{|c|}{ Low } & \multicolumn{2}{|c|}{ Low } \\
\hline
\end{tabular}

\begin{tabular}{|c|c|c|c|c|c|c|c|c|c|c|c|c|}
\hline \multirow{3}{*}{$\frac{\text { Level }}{\text { High }}$} & \multicolumn{4}{|c|}{ Comprehension } & \multicolumn{4}{|c|}{ Application } & \multicolumn{4}{|c|}{ Analysis } \\
\hline & \multicolumn{2}{|c|}{ Experimental } & \multicolumn{2}{|c|}{ Control } & \multicolumn{2}{|c|}{ Experimental } & \multicolumn{2}{|c|}{ Control } & \multicolumn{2}{|c|}{ Experimental } & \multicolumn{2}{|c|}{ Control } \\
\hline & 6 & 14.3 & 0 & 0.0 & 8 & 19 & 1 & 2.4 & 3 & 7.1 & 0 & 0.00 \\
\hline Average & 27 & 64.3 & 21 & 52 & 31 & 74 & 22 & 53.7 & 32 & 76.2 & 21 & 61.0 \\
\hline Low & 9 & 21.4 & 20 & 49 & 3 & 7 & 18 & 43.9 & 7 & 16.7 & 20 & 39.0 \\
\hline Overall & 42 & 100 & 41 & 100 & 42 & 100 & 41 & 100 & 42 & 100 & 41 & 100 \\
\hline Mean & \multicolumn{2}{|c|}{12.21} & \multicolumn{2}{|c|}{8.56} & \multicolumn{2}{|c|}{11.74} & \multicolumn{2}{|c|}{8.66} & \multicolumn{2}{|c|}{14.17} & \multicolumn{2}{|c|}{10.56} \\
\hline Interpretation & \multicolumn{2}{|c|}{ Average } & & rage & \multicolumn{2}{|c|}{ Average } & \multicolumn{2}{|c|}{ Average } & \multicolumn{2}{|c|}{ Average } & \multicolumn{2}{|c|}{ Average } \\
\hline \multicolumn{13}{|l|}{ Legend: } \\
\hline Level & \multicolumn{3}{|c|}{ Comprehension } & \multicolumn{3}{|c|}{ Application } & \multicolumn{2}{|c|}{ Analysis } & \multicolumn{3}{|c|}{ Overall } & \\
\hline High & 16. & -24.0 & & 14.01 & -2 & & & -30.00 & 50 . & & & \\
\hline Average & 8. & -16.0 & & 7.01 & & & & -20.00 & 25 . & & & \\
\hline Low & 0. & -8.00 & & 0.00 & & & & -10.00 & 0. & & & \\
\hline
\end{tabular}




\subsubsection{Application Skill}

Based on the pretest results, in line with the application skill, the mean in the experimental group is 1.98 while, the mean in the control group is 1.80 . After the treatment, students in the experimental group got a mean of 11.74 and the control group got 8.66 (Table 2). The skill in calculating concentration of solutions is not yet developed. However, after the intervention, students in the experimental group got a mean of 11.74 and the control group got 8.66. Students in the constructivist classroom can better solve problems on concentration of solutions thus, the application skill is better enhanced in the experimental group. They could already apply what was learned in the classroom regarding the ways of expressing concentration of solution. The designed activities such as the 'YOU DECIDE: Heavy Metal Ions Activity' enhanced better the problem-solving skill of students in the experimental group. Students in the experimental could better solved problems on concentration of solutions because the developed activities allowed them to integrate new conceptions of the said topic to other situation. This result conforms to Janjai (2012) that lessons using instructional model based on the theories of constructivism and metacognition, significantly improved students' achievement. Even teachers experienced transition that lead to greater understanding as they acquired experience with respect to constructivism (Niaz, 2008). Hence, students through teacher's designed activities and instructional models, could developed functional literary where they could apply and appreciate their knowledge to real life situations.

\subsubsection{Analysis Skill}

Along analysis skill, the mean in the experimental group is 3.62 while, the mean in the control group is 3.98 based on their pretest results. After the treatment, the mean in the experimental group is 14.17 while, the mean in the control group is 10.56 (Table 2). Before the intervention, all learners in both groups have not yet developed their analysis skills. Subject teachers should really have designed instructional materials that will help the students develop higher order thinking skills. The learning activities in the constructivist classroom helped in enhancing the analysis skill of the students. It could be observed that the students in the experimental class can better analyze, break down, compare, contrast, infer, and distinguish between facts and inferences. The student's answer in one of the activities further proved that the students in the class using constructivist approach could analyze and explain more clearly the reason why the amount of dissolved oxygen will decrease when temperature increases. This indicates that the analysis skill in the experimental group is improved through the activities provided by the facilitator such as designing an experiment; using drawings, figures, graphics, graphs or tables; which will show how the different factors affect solubility.

The constructivist approach is a very good medium to use in teaching to enhance students' higher thinking skills. Learning is more meaningful if students construct their own knowledge and understanding. Here are some of the reflections written in the students' journal in the constructivist class: 1.) topics on Solution were thoroughly discussed, 2.) strategy used was good, and 3.) they better understood the topic if they themselves figured out their own misconceptions. It proved that students' skills in comprehension, analysis, and application in the experimental group were truly enhanced using the constructivist approach in teaching chemistry concepts and principles. The study of Jackman and Mollenberg (1987) on the relative effectiveness of different instructional approaches on college chemistry laboratory achievement conforms to the result of the present study. Moreover, the study of Kovac (1999) initiated the use of student active learning methods (SAL) in off- sequence sections of Chemistry 120 and 130 where learners are actively and interactively involved to enhance students' achievement. 


\subsection{Difference in the Level of Achievement of the Experimental Group from the Control Group after the Exposure to the Constructivist Approach}

This section presents the importance of the use of constructivist approach as shown in the comparative gains obtained by the experimental and control groups. Table 3 shows the effect size (ES) derived from the difference between the pretest and posttest gains between the experimental and control groups.

Table 3.

Effect size results in the posttest gain scores

\begin{tabular}{llcccc}
\hline \multirow{2}{*}{ Skill } & Group & Mean Gain & $\begin{array}{c}\text { Gain Standard } \\
\text { Deviation }\end{array}$ & $\begin{array}{c}\text { Effect } \\
\text { Size }\end{array}$ & $\begin{array}{c}\text { Level of } \\
\text { Significance }\end{array}$ \\
\hline \multirow{2}{*}{ Comprehension } & Experimental & 8.71 & 4.22 & 1.33 & Important \\
& Control & 5.12 & 2.69 & & \\
\multirow{2}{*}{ Application } & Experimental & 9.76 & 3.08 & 1.00 & Important \\
& Control & 6.85 & 2.90 & & \\
Analysis & Experimental & 10.55 & 4.65 & 1.23 & Important \\
& Control & 6.59 & 3.23 & & \\
Overall & Experimental & 29.02 & 10.34 & 1.58 & Important \\
\hline
\end{tabular}

Guide:

Effect Size $>0.5$ - Significant

Effect Size $<0.5$ - Not Significant

With respect to the comprehension skill, the experimental group obtained a mean gain of 8.71 $(\mathrm{SD}=4.22)$ while the control group obtained a mean gain of $5.12(\mathrm{SD}=2.69)$. The computed effect size is 1.336. An effect size of 0.50 or larger, according to Fraenkle and Wallen (2006) may be interpreted as important. It may therefore be said that the achievement levels of the two groups along comprehension skill differed, with the experimental group's mean gain registering considerable difference over that of the control group. Students from the experimental group could better comprehend, defend, distinguish, and explain. It implies that the activities in the constructivist approach lead the learners to actively create and restructure knowledge on Solutions.

Along application, the computed effect size shows that the achievement levels of the two groups has differ with the students in the experimental group showing greater improvement in their application skill (ES=1.0). It is evident that students can apply, construct, and compute for the concentration of solutions. Their group outputs proved that there is indeed an improvement in their problem-solving skills. Some students cited that this skill can be applied even in solving environmental, personal and family problem. Some said they can use it in making decisions.

In the analysis skill, the computed effect size (ES=1.23) shows that the achievement level of the two groups likewise differed with the students in the experimental group obtaining bigger mean gain. The activities using the constructivist approach further enhanced their skill in making inferences and finding evidence to support generalizations.

Overall, the computed effect size of 1.581 reveals that level of achievement of the two groups differed with the experimental group showing important gain. Hence, the group exposed to the constructivist approach performed better than the group exposed to the traditional method of teaching. This is supported by the presented experimental evidence. The study of Molina (2001) showed that the interactive method of teaching improved the students' achievement in chemistry and their attitude towards the subject. This conclusion is consistent with the results of the present study. Teachers, educators, and administrators should have a full grasp of the principles and theories of the constructivist view of learning for a more effective teaching and learning practices. 


\subsection{Factors in the Constructivist Approach that Contribute to Students' Achievement}

Table 4 shows the correlation coefficients determining the specific factors that significantly contributed to students' achievement. In this table, the negative correlation coefficient indicates that the raw scores in the achievement test per cognitive skill were inversely proportional to the raw scores in the constructivist attitudinaire. It means that if the students' raw score in the comprehension level were high, their raw scores in the constructivist attitudinaire were low. Likewise, if the scores in the comprehension level were low, the scores in the attitudinaire were high. The same trend was observed to other cognitive skills. However, the absolute value of the correlation coefficient was used in comparing it to the critical values.

Table 4.

Correlation Coefficients of Factors that Affect Students Achievement

\begin{tabular}{|c|c|c|c|c|c|c|c|c|c|c|c|}
\hline \multirow{2}{*}{ Achievement } & \multicolumn{8}{|c|}{ Factors } & \multicolumn{3}{|c|}{ Critical Value } \\
\hline & \multicolumn{2}{|c|}{ A } & \multicolumn{2}{|c|}{$\mathrm{B}$} & \multicolumn{2}{|c|}{$\mathrm{C}$} & \multicolumn{2}{|c|}{$\mathrm{D}$} & $\mathrm{df}$ & $5 \%$ & $1 \%$ \\
\hline Comprehension & -0.468 & $H S$ & -0.306 & $S$ & -0.305 & $S$ & -0.211 & $N S$ & & & \\
\hline Application & -0.235 & $N S$ & -0.486 & $H S$ & 0.030 & $N S$ & -0.032 & $N S$ & 40 & 03 & 030 \\
\hline Analysis & -0.462 & $H S$ & -0.163 & $N S$ & -0.115 & $N S$ & -0.125 & $N S$ & 40 & 0.3 & 0.39 \\
\hline Overall & -0.463 & $H S$ & -0.351 & $S$ & -0.163 & $N S$ & -0.128 & $N S$ & & & \\
\hline
\end{tabular}

Legend: HS - Highly Significant; S - Significant; NS - Not Significant

A - Constructivist Strategies

B - Students Involvement During Class Discussion

C - Students Participation in Lab Activities

D - Perception of Students

Along comprehension, the constructivist strategies employed in the lesson had a correlation coefficient of -0.468 . The coefficient shows that the constructivist strategies had high significant correlation with comprehension, no significant contribution to application, and high significant correlation with analysis. The experimental evidence can be substantiated by the entries in the students' journal that they like the teaching strategies used in the lessons but, what they disliked was group members who are passive and uncooperative. The correlation coefficients of students' involvement during class discussion show significant correlation with comprehension and application, no correlation with analysis. Furthermore, students' participation in laboratory experiments and group activities along application and analysis, and students' perception have no significant correlation to students' achievement in terms of the three cognitive skills.

The following factors in the constructivist approach namely: constructivist strategies employed in the lesson, and students' involvements during class discussion have significant contribution to students' achievement. This finding is supported by the entries written in the students' journal. Most of the students wrote that the strategies used by the teacher helped them understand the lesson and encourage them to ask relevant questions. Some students even wrote that they enjoyed the discussion and interactions with other students, and have learned to love and see the importance of chemistry to real life. But few students directly mentioned regarding the significance of the constructivist approach in the improvement of their level of achievement. Students expressed further desire to know chemistry and hoped that chemistry will develop their creativity and innovativeness. It shows that using the constructivist view of learning, students become more reflective, inquisitive, active, and responsible decision-makers. This conforms to the study of Cobb, Wood, and Yackel (in Jimena, 2002).

Furthermore, the creation of an environment that supports the active involvement of students in collaborative and empowering activities such as the exchange of ideas and opinions, improve students' achievement. Hence, teachers should always provide an environment that promotes students' empowerment wherein they are directly involved in all matters that occur in the classroom. It is important for the teachers to establish a democratic classroom environment that gives emphasis on shared responsibility and decision making. 
Table 5 shows the correlation coefficients determining the specific factors that significantly contributed to students' attitude. It is logical to see negative correlation coefficient since the raw score in the chemistry attitudinaire was inversely proportional to the raw scores in the constructivist checklist. It means that if the students' raw score in the chemistry attitudinaire were high, their raw scores in the constructivist checklist were low. On the same manner, if the scores in the attitudinaire were low, the scores in the checklist were high. However, the absolute value of the correlation coefficient was used in comparing it to the critical values. The coefficients correlation of constructivist strategies employed in the lesson and the students' involvement during class discussion have high significant correlation with students' attitude. On the other hand, students' participation in laboratory activities and students' perception have no significant bearing to students' attitude.

Table 5.

Correlation coefficients on factors that affect students' attitude

\begin{tabular}{|c|c|c|c|c|c|c|c|c|c|c|c|}
\hline \multirow{2}{*}{ Attitude } & \multicolumn{8}{|c|}{ Factors } & \multicolumn{3}{|c|}{ Critical Value } \\
\hline & A & & B & & C & & D & & Df & $5 \%$ & $1 \%$ \\
\hline Computed Value & -0.464 & $H S$ & -0.523 & $H S$ & -0.143 & $N S$ & -0.020 & $N S$ & 40 & 0.30 & 0.39 \\
\hline
\end{tabular}

Legend:

HS - Highly Significant (significant at 1\% \& 5\%); S - Significant; NS - Not Significant

A - Constructivist Strategies

B - Students Involvement During Class Discussion

C - Students Participation in Lab Activities

D - Perception of Students

This data is supported by the entries written in the students' journal showing a positive attitude towards Chemistry and the approach. The result conforms with Berg's (2005) study; he determined the factors associated with changes in attitude towards learning chemistry. A positive attitude change was associated with evidence of motivated behavior, while a negative change was linked to less motivated behavior. The constructivist approach, due to the teacher's employed strategies in the lessons and designed classroom activities, significantly enhanced both the students' level of achievement and students' attitude toward chemistry. Thus, educators should adopt the constructivist approach in teaching chemistry by using constructivist strategies and well-designed activities to improve students' level of achievement and develop a positive attitude towards the subject.

\section{Acknowledgements}

The author would like to acknowledge respondents who actively participated in the quasiexperimental research, experts who validated the instruments used in the study, Bicol University, Ateneo de Naga University, and National Library for their contributions in the realization of this study.

\section{References}

Avci, F., Sesen, B., and Kirbaslar, F. (2014). Determination of Seventh Grade Students' Understanding of Certain Chemistry Concepts. Procedia - Social and Behavioral Sciences, 152 (7), 602-606.

Butts and Smith. (1987). HSC Chemistry Students' Understanding of the Structure and Properties of Molecular and Ionic Compounds. Research in Science Education, 17, 192 208.

Driver, R. and Oldham, V. (1986). A Constructivist Approach to Curriculum Development in Science. Journal in Science Education, 13 (4). 
Janjai, S. (2012). Improvement of the Ability of the Students in an Education Program to Design the Lesson Plans by Using an Instructional Model based on Constructivism and Metacognition. Procedia Engineeering 32. 1163-1168.

Matchete, E. (2001). Performance of Third Year High School Students in Chemistry: An Assessment. Unpublished Master's Thesis.

National Center for Education Statistics". Institute of Education Sciences. US Department of Education. nces.ed.gov/TIMSS.

Niaz, M. (2008). Whither Constructivism? - A Chemistry Teachers' Perspective. Teaching and Teacher Education 24 (2). 400-416.

Secken, N. (2010). Identifying Students' Misconceptions about Salt. Procedia - Social and Behavioral Sciences. 2 (2), 234-245.

Sutaria, M. (1985). Status of Science Education in the Philippines Elementary Level. 34 ${ }^{\text {th }}$ PhilAAS Annual Convention Symposia.

Tan, et al. (2001). Development and Application of a Two-tier Multiple-Choice Diagnostic Instrument to Assess High School Students' Understanding of Inorganic Chemistry Qualitative Analysis. Journal of Research in Science Teaching. 39 (4), 18-24.

Tsaparlis, G. (2016). Problems and Solutions in Chemistry Education. Journal of the Turkish Chemical Society, 1 (1), 1-30. 